\title{
SUITABILITY OF TAPERED FLANGE I-SECTIONS IN SEISMIC MOMENT RESISTING FRAMES
}

\author{
R. Goswami ${ }^{1}$ and C.V.R. Murty ${ }^{2, *}$ \\ ${ }^{1}$ Ph.D. Scholar, Department of Civil Engineering, \\ Indian Institute of Technology Kanpur, Kanpur 208016, India \\ ${ }^{2}$ Professor, Department of Civil Engineering, \\ Indian Institute of Technology Kanpur, Kanpur 208016, India \\ * (Corresponding author: E-mail: cvrm@itk.ac.in)
}

Received: 18 December 2007; Revised: 16 February 2008; Accepted: 4 March 2008

\begin{abstract}
Tapered flange sections offer difficulties of providing connections that are expected to resist overstrength plastic moments of members and associated shear. However, some earthquake prone countries still are using tapered flange sections for constructing buildings to resist severe seismic shaking. Tapered flange sections available in India not only offer low sections properties (moment of inertia $I$, flange width $b$ ), but also do not meet the internationally accepted stability requirements. This paper highlights deficiencies in tapered flange sections and reiterates some important issues in earthquake-resistant connection design.
\end{abstract}

Keywords: Tapered flange sections; seismic design; moment frames; stability; compact section; connection design; plastic; overstrength

\section{INTRODUCTION}

Satisfactory performance of steel structures in high seismic regions primarily depends on three factors in design namely strength, stability and ductility of individual members. Apart from these, connections play an important role in the overall performance of the structure; inadequate connections can result in failure of the structure even if the structural members are adequately designed. Designed connections, together with a predetermined collapse mechanism under strong seismic shaking can result in good overall performance of the structure. In many Asian countries, including India, hot-rolled tapered flange sections are still commonly used in construction of multi-storey steel frame buildings. This paper reviews international state-of-the-art seismic design specifications for steel I-sections and evaluates the suitability of tapered-flange sections use in high seismic areas.

\section{EARTHQUAKE HAZARD AND STEEL CONSTRUCTION - THE INDIAN SCENARIO}

Over the past two decades, India has experienced a spate of earthquakes that caused large damage to residential and industrial structures (i.e., 1984 M5.6 Cachar earthquake, 1988 M6.6 Bihar earthquake, 1991 M6.6 Uttarkashi earthquake, 1993 M6.4 Killari earthquake, 1997 M6.0 Jabalpur earthquake, 1999 M6.5 Chamoli earthquake, 2001 M7.7 Bhuj earthquake, 2002 M6.5 Diglipur earthquake, 2004 M9.3 Sumatra earthquake, and 2005 M7.7 Kashmir earthquake). Besides, during the five decades from 1897 - 1950, India had experienced four great earthquakes (M>8), i.e., 1897 M8.7 Assam earthquake, 1905 M8.6 Kangra earthquake, 1934 M8.4 Bihar-Nepal earthquake and the 1950 M8.6 Assam-Tibet earthquake. Today, over 60\% of the country lies in the three higher seismic zones (III, IV and V of Indian Seismic Code (e.g. IS 1893 Part 1 [1]) and only about $3 \%$ of the built environment (of over 250 million houses) is engineered. Even these engineered structures are under suspect owing to poor seismic design practice. Thus, India has potential for strong seismic shaking, and the large stocks of existing buildings are vulnerable. The situation is similar in 
many neighbouring countries. In general, reinforced concrete and masonry are still the common choice over steel as a building material. However, recent trends in some of these countries show substantial growth in steel consumption. This is largely attributed to increase in low-to-medium rise residential and office buildings in urban centers. For this, available hot-rolled standard tapered-flange sections are being used.

\section{SECTION GEOMETRY}

An important feature of tapered flange sections is the slope in the flange thickness. Due to this slope or taper, bolt-shank bends on tightening thereby increasing the chances of its failure. Also, because of the tapered and thin tip of the flange, only small size welds are possible between the cover plate and the flange tip (Figure 1). Moreover, proper welding between surfaces at such obtuse angle is difficult; also, it increases chance of brittle failure of the weld. Another concern is the small flange width of the sections; the largest is only $250 \mathrm{~mm}$ wide. Small flange width allows use of only one bolt on either side of the web and therefore requires unduly large connection length. Poor and unreliable welding in welded connection scheme and large connection length in bolted connection scheme puts the cover-plated connections of tapered flange sections in jeopardy; only hot-rolled sections with uniform thickness flanges should be used in seismic applications as in countries with advanced provisions in seismic design of steel structures, like the USA [2, 3].

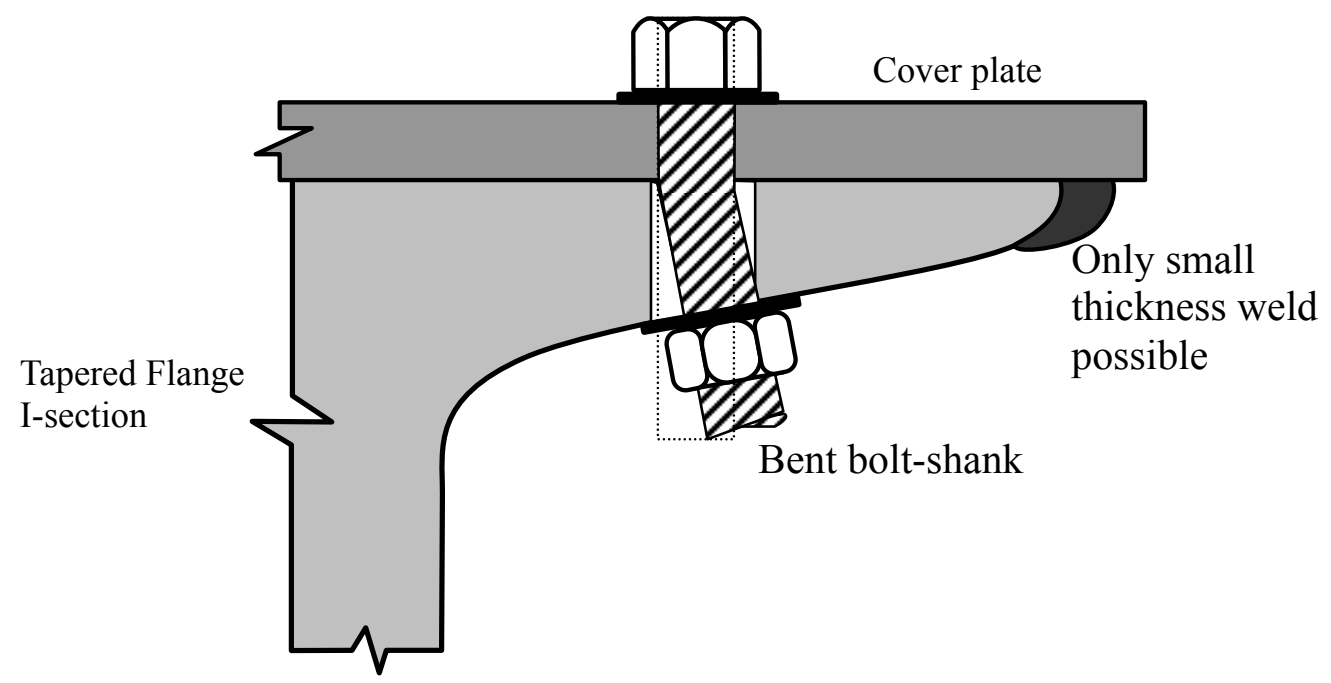

Figure 1. Effects of Tapered Flange: (i) Bolted Connection: Bolt Shank gets Bent on Tightening from the Original Straight Alignment and (ii) Welded Connection: Only Obtuse Angled Small Thickness Weld Possible at the Tapered Tip

\section{STABILITY}

Steel as a material has intrinsic ductility. But, the ductility in steel structures is primarily achieved through a design and construction process that ensures stable post-yield behaviour of the material. This entails stringent stability provisions that ensure formation of plastic hinges. 
Considering the major instabilities in steel structures (e.g., lateral torsional buckling of beams, flexural buckling of columns, and local buckling of beam-column flanges and webs), and the expected level of inelastic deformation and ultimate strength achieved, sections are grouped as compact, semi-compact and slender sections. Design codes use slenderness or $b / t$ ratios to identify stability limits of flange and web plates to demarcate these groups of sections. The AISC Specifications (e.g. Specifications for Structural Steel Buildings [2]) and Provisions (e.g. Seismic Provisions for Structural Steel Buildings [3]) have these limits as: (a) $\lambda_{p s}$ : slenderness limit for compact elements with a minimum guaranteed ultimate strength $M_{p}$ (nominal plastic moment capacity) and plastic rotation ductility, (b) $\lambda_{p}$ : slenderness limit for compact elements with only minimum guaranteed strength $M_{p}$, and (c) $\lambda_{r}$ : slenderness limit for non-compact elements with only minimum guaranteed strength $M_{y}$ (Figure 2). Sections with slenderness ratio $\lambda$ of flanges and web elements $>\lambda_{r}$, classified as slender sections buckle locally even before reaching their yield moment capacity $M_{y}$. Sections with $\lambda_{p}<\lambda<\lambda_{r}$, classified as non-compact sections just reach the yield moment. Sections with $\lambda_{p s}<\lambda<\lambda_{p}$, classified as compact sections, develop the member plastic capacity $M_{p}$ with limited ductility, while sections with $\lambda$ less than $\lambda_{p s}$ develop full member plastic capacity $M_{p}$ and sufficient plastic rotation.

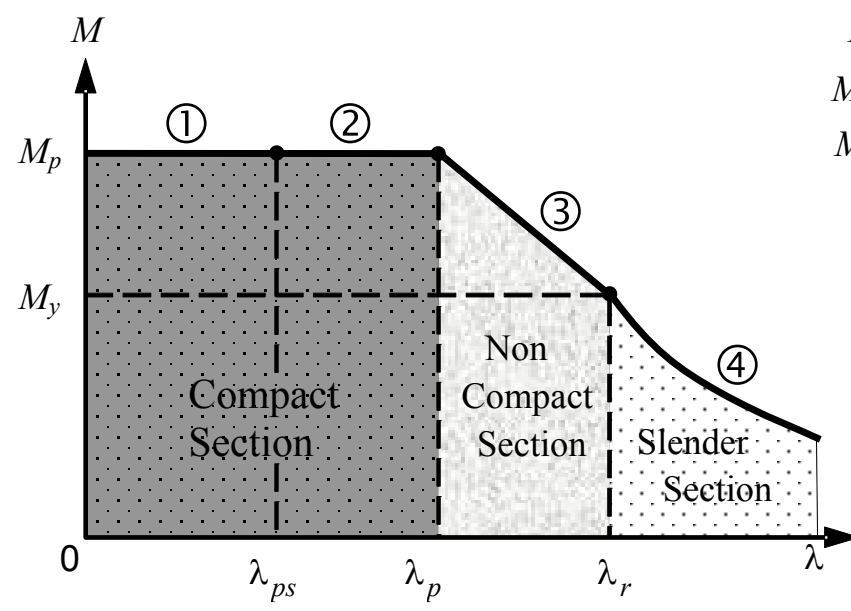

(a)

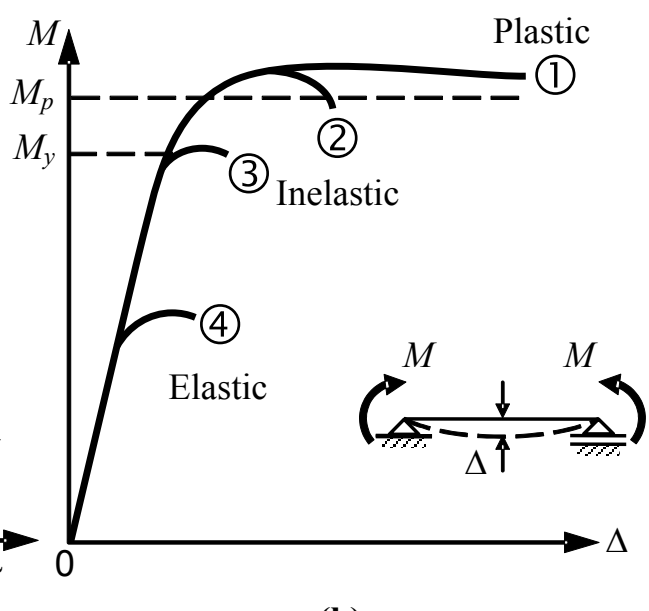

(b)

Figure 2. Effect of Slenderness on Developable Member Capacity:

(a) Strength-Slenderness Ratio Relationship; (b) Moment-Deflection Behavior of I-Sections, for Different Levels of Slenderness. Inelastic Buckling Commences much before Yield Moment $M_{y}$ is Reached because of Residual Stresses

For steel with nominal yield strength $F_{y}=250 \mathrm{MPa}$, the above slenderness limits are presented. Plastic design in the Indian Standard (IS-PD) (e.g. IS 800 [4]) limits the maximum unsupported flange width-to-thickness ratio to 8.6, and the maximum web depth-to-thickness ratio to 43.5 for $P / P_{y}$ exceeding $0.27,70.8$ for zero axial force, and linearly varying for intermediate axial force values. In comparison, the AISC Load and Resistance Factor Design specifications (AISC-LRFD) (e.g. Specifications for Structural Steel Buildings [2]) limits maximum unsupported flange width-to-thickness ratio to 10.7 for compact sections and to 28.2 for non-compact sections. And, the web depth-to-thickness ratio is limited to 106.2 for compact sections and 161.2 for non-compact sections. The AISC Provisions (e.g. Seismic Provisions for Structural Steel Buildings [3]) limits are even more stringent: 8.5 for beam flange and 69.2 for beam web of seismically compact sections, and 42.1 for column webs. 
The Indian Standard Handbook (e.g. SP: 6(1) [5]) classifies Indian Standard hot-rolled I-section beams into four categories namely, light (ISLB), medium (ISMB), wide flange (ISWB) and heavy (ISHB). These sections (originally used in British practice) have unique feature of tapered flanges with rounded corners at the flange tips. For the purpose of design, a nominal thickness is used for these tapered flanges. The comparison of width-to-thickness ratios of flange and web plates of the available and commonly used hot-rolled tapered flange I-shaped sections used in India are shown in Figures 3 and 4. The cross-sectional dimensions can be found elsewhere (e.g. SP: 6(1) [5]). The flange and web width-to-thickness ratios of sections with maximum depth of $600 \mathrm{~mm}$ or flange width of $250 \mathrm{~mm}$, do not comply with the seismically compact section limits. Hence, structures made with these sections are seismically deficient.

Apart from section compactness, member stability is another important requirement for good seismic performance of the structure. IS-PD limits maximum slenderness ratio to 120 for columns. AISC Specifications limits maximum slenderness ratio to 133 for columns when inelastic analysis and design are performed. For the usual storey height, tapered flange sections fail to comply with required member slenderness for columns under strong seismic action because of their small radius of gyration; additional flange plates are required if these sections are to be used in moment resisting frames (MRFs) intended to resist seismic actions (e.g. Paul, Murty and Jain [6]). As a result, it is expected that these frames built with these sections would exhibit a poor post-yield behaviour, under strong seismic shaking.

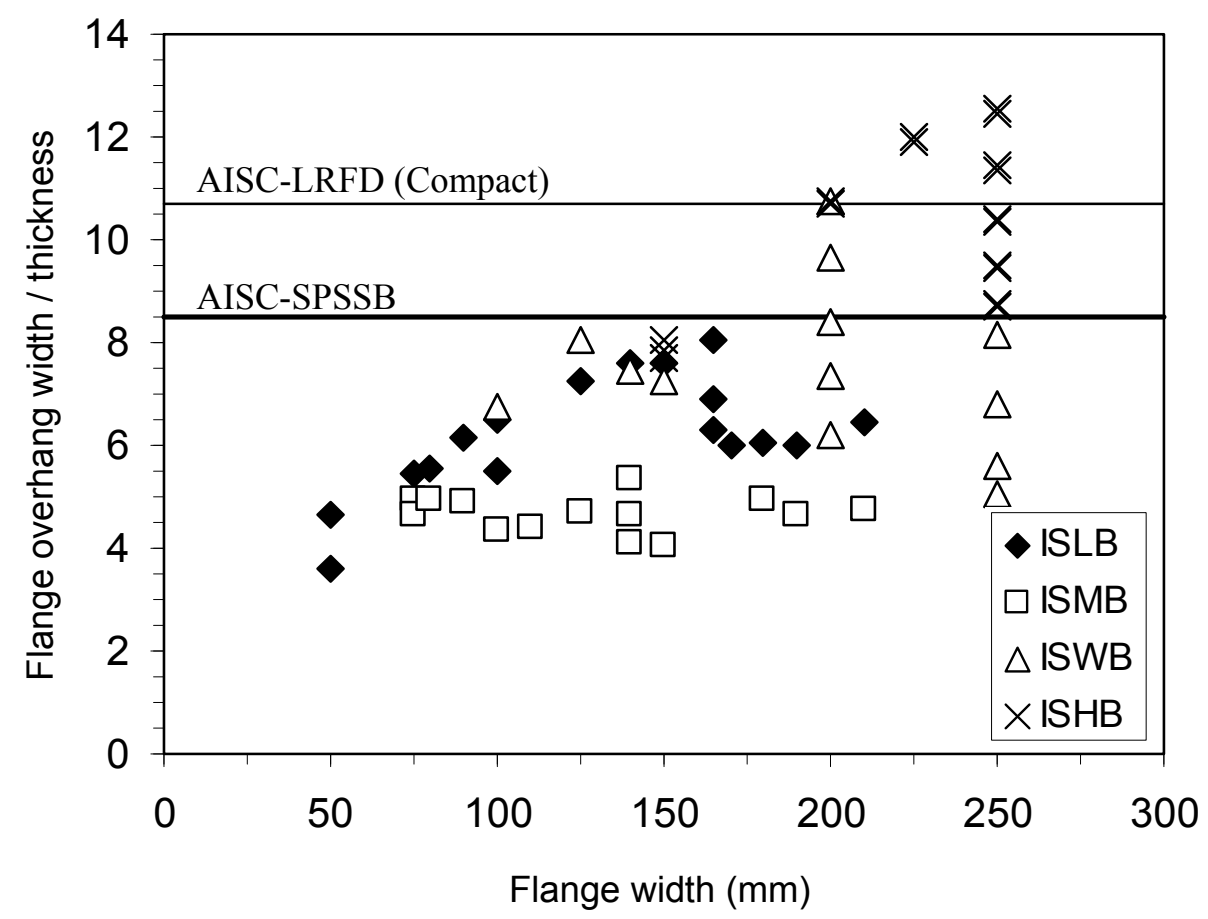

Figure 3. Flange Width-to-Thickness Ratio of Indian Hot-Rolled Tapered Flange I-Sections: Some Sections do not Comply with the Seismically Compact Section Limit Even when the Maximum Available Flange Width is only $250 \mathrm{~mm}$ 


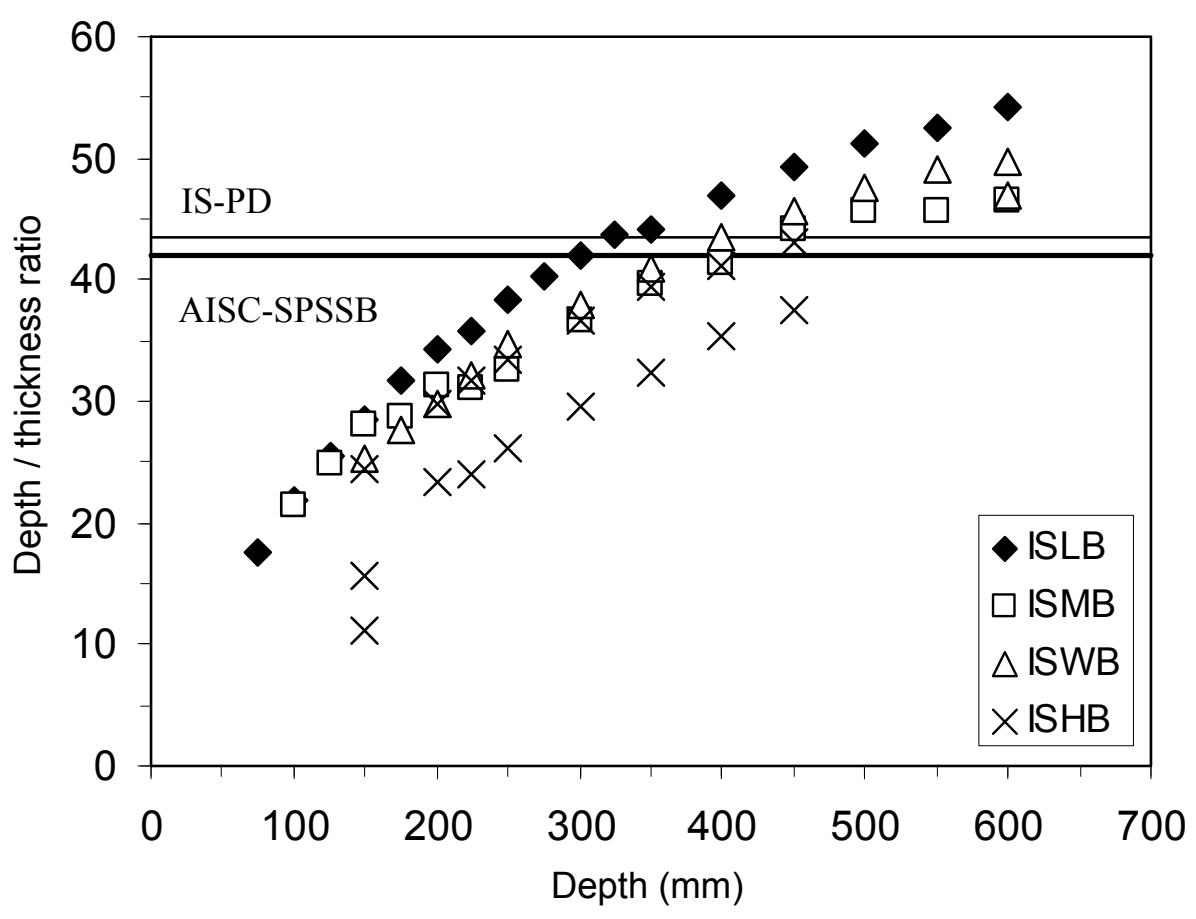

Figure 4. Web Depth-to-Thickness Ratio of Indian Hot-Rolled Tapered Flange I-Sections: Sections with Higher Depth do not Comply with the Seismically Compact Section Limit even when the Maximum Available Depth is only $600 \mathrm{~mm}$

\section{STIFFNESS AND STRENGTH}

A comparison is made of stiffness and strength of the tapered flange sections with representative parallel wide flange AISC sections commonly used in seismic design (Tables 1 and 2). The maximum depth of Indian tapered flange sections is $600 \mathrm{~mm}$, and the largest moment of inertia $I_{x x}$ (about strong axis of bending) and nominal plastic moment capacity $M_{p}$ are $1156 \times 10^{-6} \mathrm{~m}^{4}$ and $987 \mathrm{kNm}$ respectively. However, $I_{x x}$ and $M_{p}$ of AISC sections of same depth are at least about 3 times higher than those of the tapered flange sections of same depth (Figures 5 and 6). Thus, structures built with even the largest tapered flange sections are too flexible and too weak relative to their international counterparts with parallel flange sections.

\section{CONNECTION DESIGN}

Following the large number of connection failures during the 1994 Northridge (USA) and 1995 Kobe (Japan) earthquakes, a fresh approach emerged for the design of beam-to-column and column-to-base connections. Beam-to-column connections are designed now as per the Capacity Design Concept. By this design method, premature fracture of welds or fasteners is avoided at the connection; beams and columns undergo ductile yielding and connections remain elastic when designed for the maximum demand arising from the beam or column under plastic condition (Figures 7 and 8). In summary, the capacity design concept enlists a strength hierarchy of the components of a building: (a) the beam-to-column connections joint are to be stronger than the beam, (b) the columns are to be stronger than the beams, and (c) the column base connections are to be stronger than the column (e.g. Penelis and Kappos, 1997 [7]). 


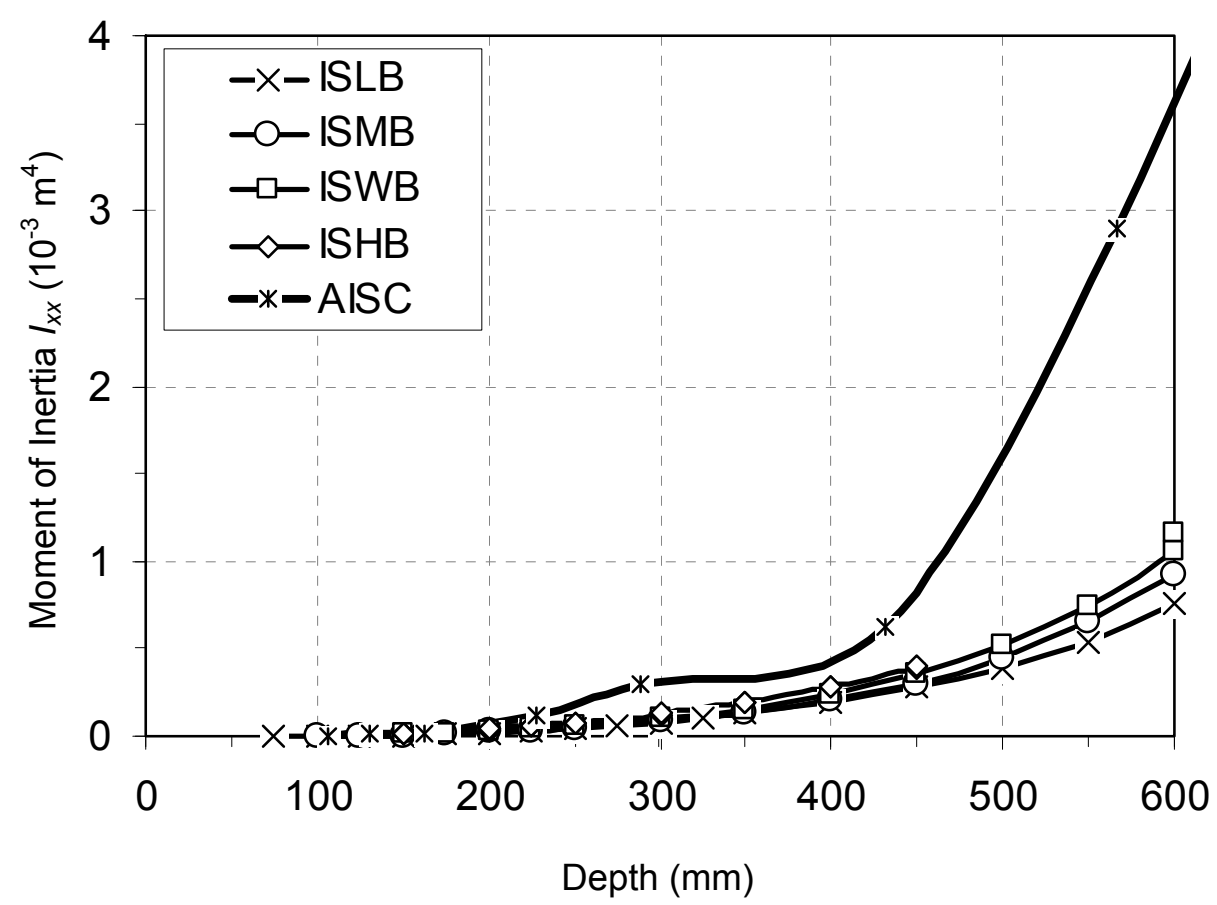

Figure 5. Comparison of Moment of Inertia of Representative AISC and IS Hot-Rolled Tapered Flange I-Sections: Tapered Flange Sections are much smaller than the AISC Parallel Wide Flange Sections

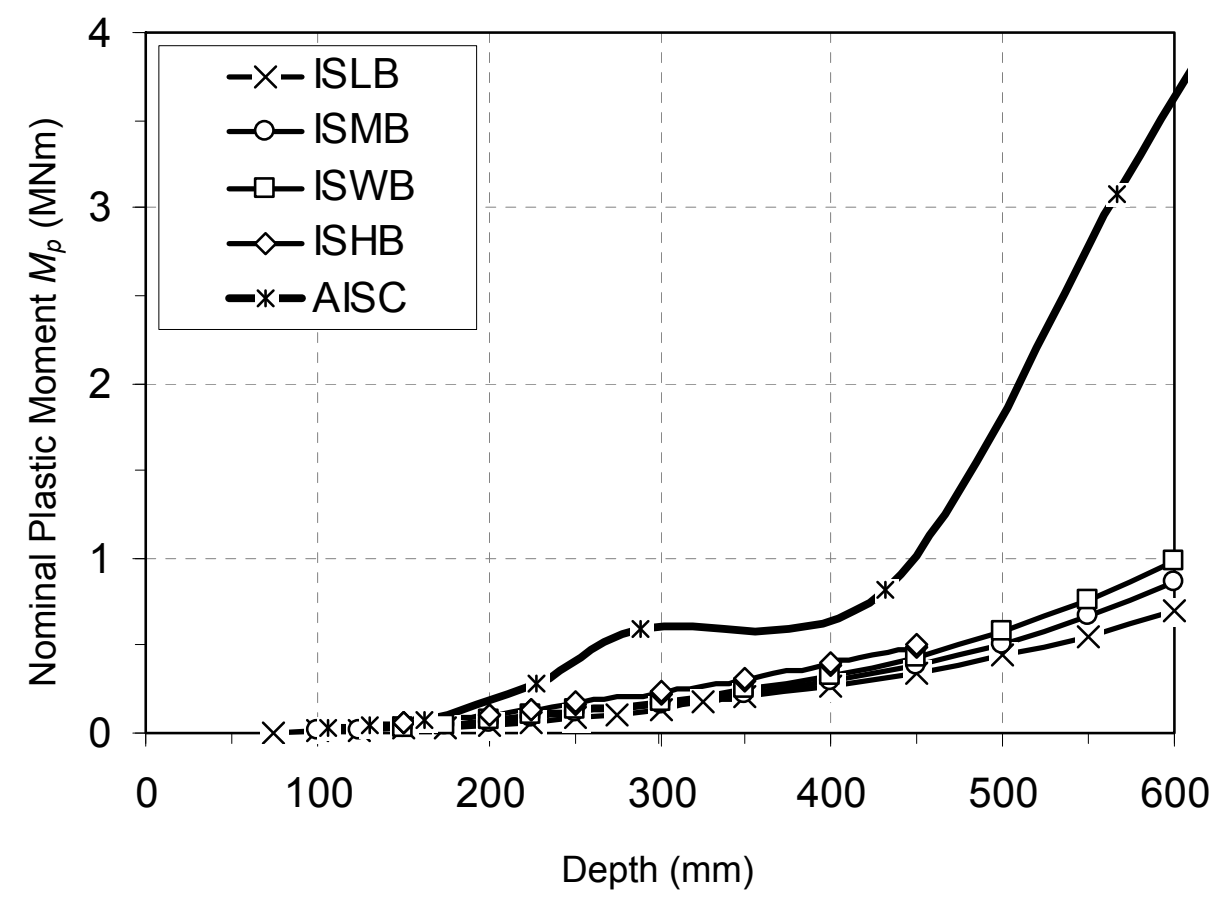

Figure 6. Comparison of Nominal Plastic Moment of Representative AISC and IS Hot-Rolled Tapered Flange I-Sections: Tapered Flange Sections are much smaller than the AISC Parallel Wide Flange Sections 

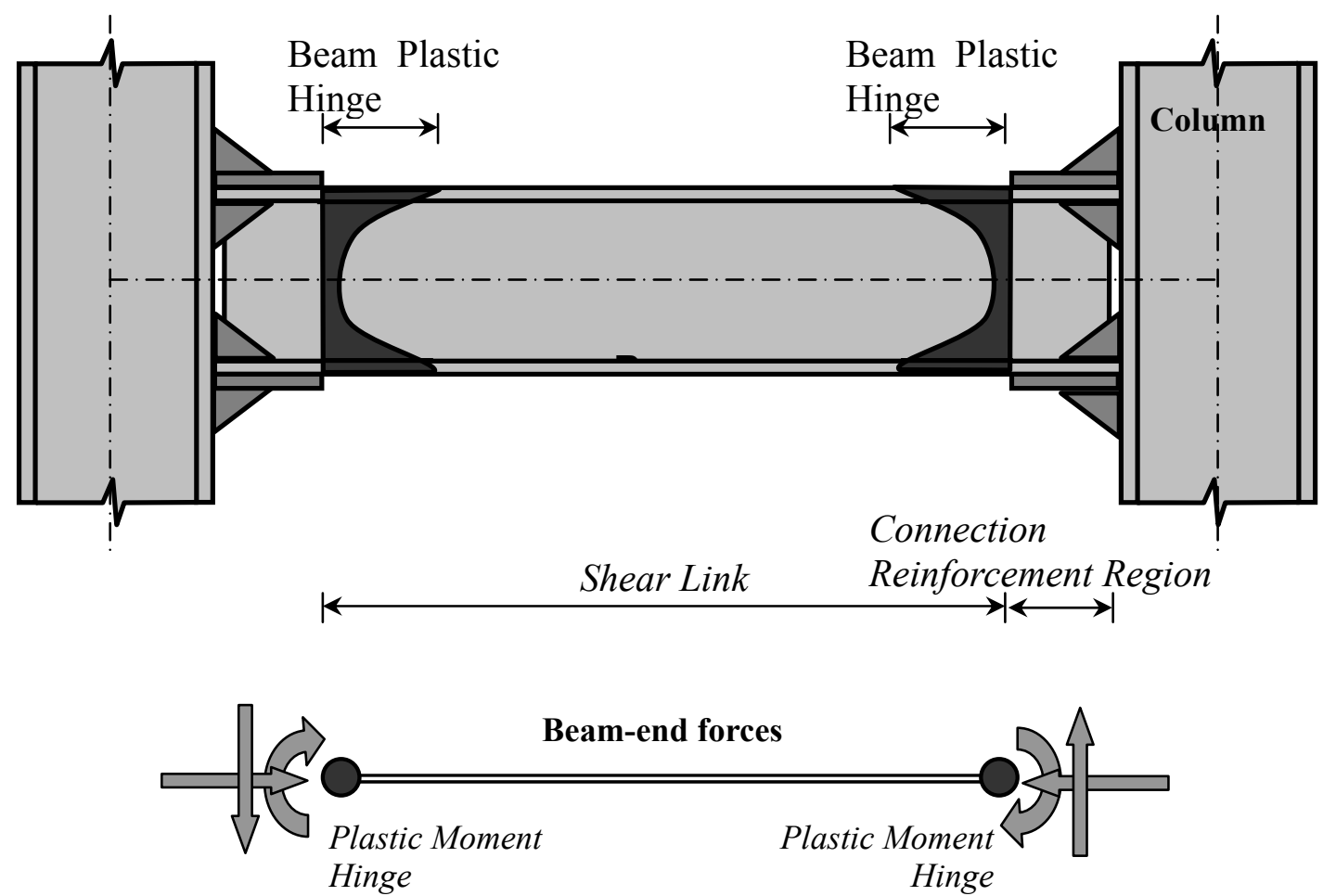

Lateral Seismic Load

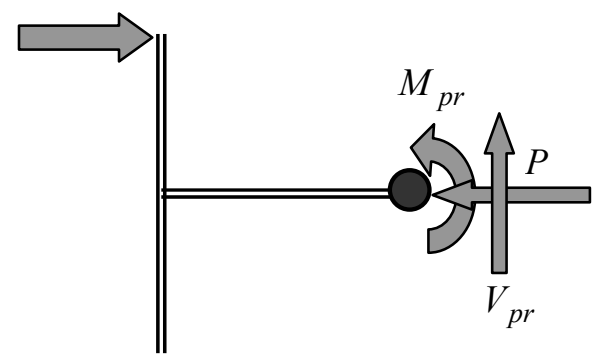

Connection forces

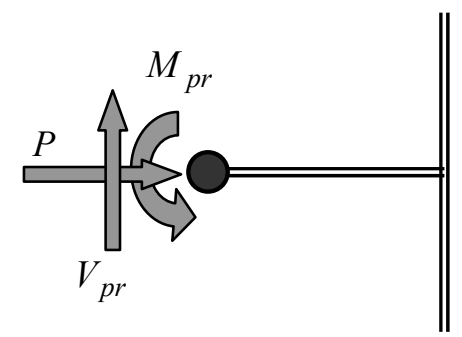

Figure 7. Location of Ductile Plastic Hinges Adjacent to Beam-to-Column Connections: Connection Reinforcement Elements help in Pushing the Inelasticity Away from the Column Face

The connection design forces should be designed for the maximum probable member strength, i.e., moment capacity $M_{p r}$ and the associated equilibrium compatible shear $V_{p r}$, including effect of gravity load. In using $M_{p r}$ in connection design, three important issues need attention. Following the Northridge and Kobe earthquakes, coupon tests of specimens taken from actual construction and mills have shown that the actual yield strength of steel in rolled-sections can be higher than the minimum specified yield strength $F_{y}$ (e.g. Engelhardt and Sabol [8]; Malley and Frank [9]). As a result, AISC Provisions recommends the use of higher yield strength for calculating member strength for the determination of connection element design force; the ratio $R_{y}$ of the expected yield strength to the minimum specified yield strength of the member is to be used. For instance, for ASTM A36 grade steel, $R_{y}$ is 1.5 ; at least a $50 \%$ increase in connection design force is recommended. However, In India, such data for the available tapered flange sections are not readily available in public literature, and also, the current code provisions do not account for this. Such statistical data from the hot-rolled tapered flange sections obtained through coupon test need to be incorporated in seismic design procedures. 


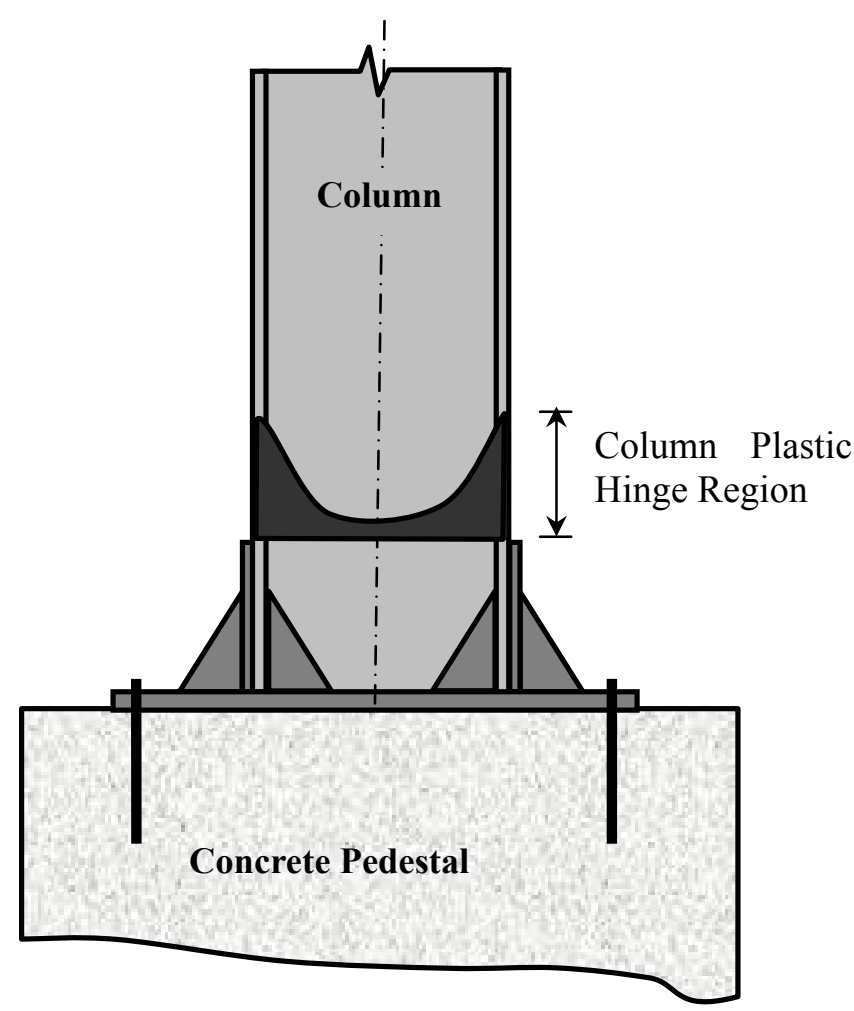

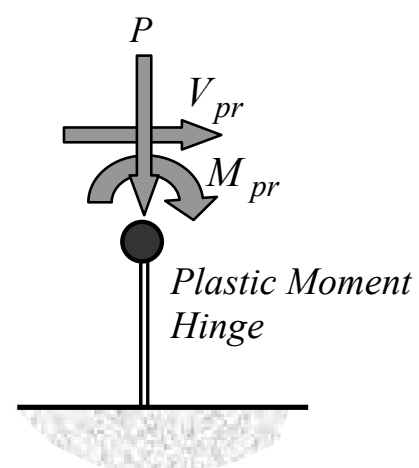

Connection forces

Figure 8. Location of Ductile Plastic Hinges Adjacent to Column-to-Foundation Connections: Connection Reinforcement Elements help in Pushing the Inelasticity away from the Base Plate

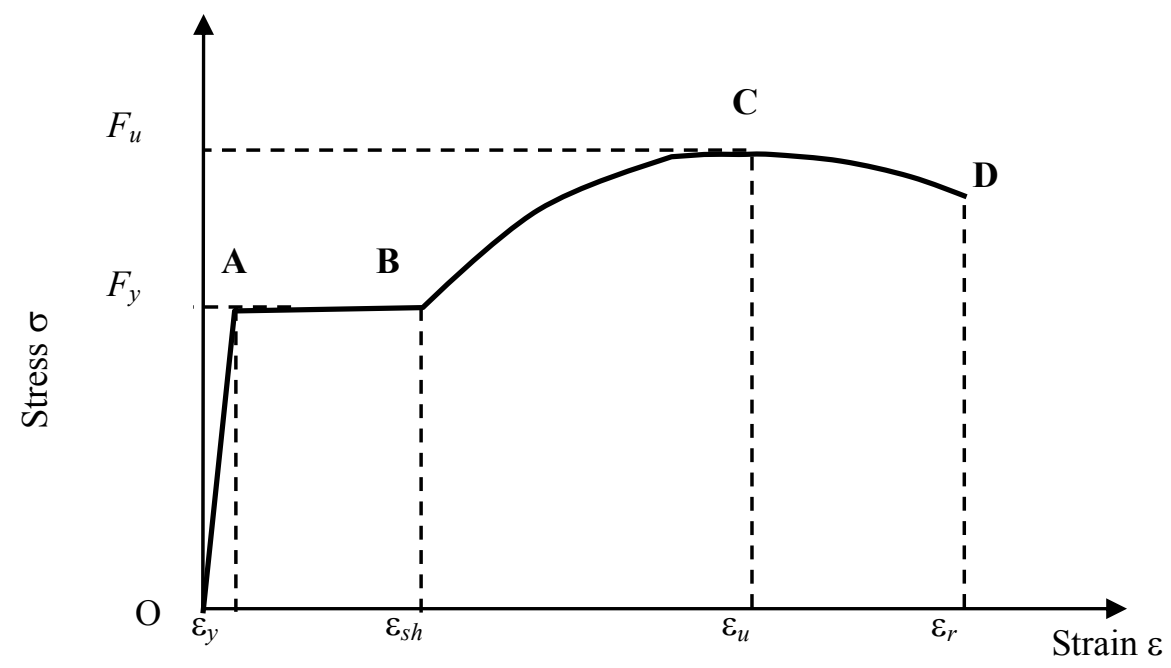

Figure 9. Typical Schematic of Constitutive Curve of Structural Steel: Four Distinct Zones are Evident - A Linear Elastic Zone OA, a Yield Plateau AB, a Strain-Hardening Zone BC and a Strain-Softening Zone CD 


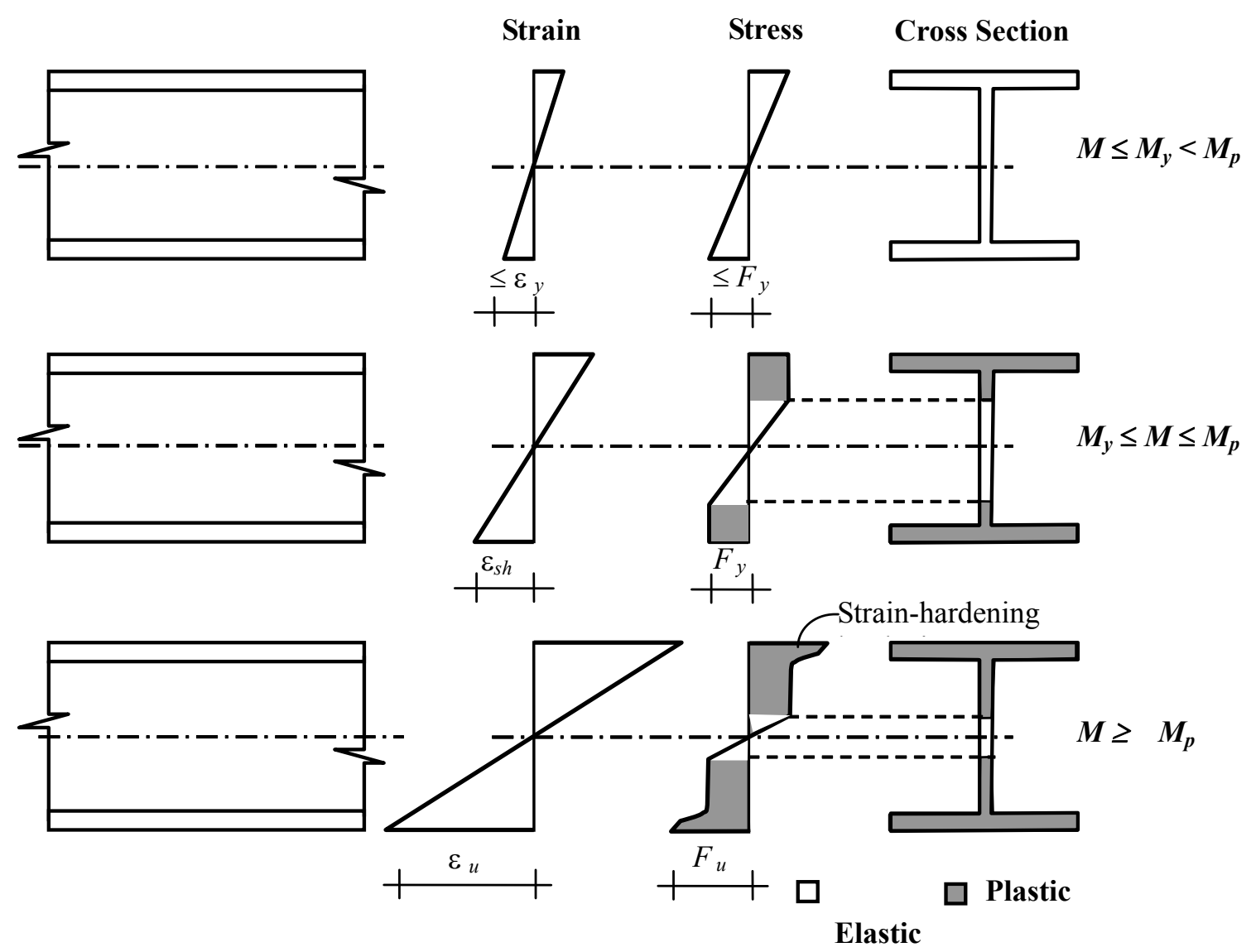

Figure 10. Various Stages of Member Plastification under Pure Flexure: The Fibers at Neutral Axis do not Yield, but the Fibers away from the Neutral Axis Strain-Harden, thus the Cross-Section Develops a Nominal Plastic Moment of $M_{p}$ and more

Design codes often (e.g., AISC [2], IS:800 [4]) assume an idealized elastic perfectly plastic constitutive law for structural steel with characteristic yield strength as $F_{y}$. In reality, structural steel has a distinct constitutive relation (Figure 9) with an initial elastic zone (OA), a yield plateau (AB), a strain hardening zone (BC), and a strain-softening zone (CD) before it fractures. The member nominal flexural capacity $M_{p}$ for bending about the major axis is computed based on the idealized rectangular stress block with a maximum stress of $F_{y}$. Such a stress block is not practically achievable, because to develop a stress of $F_{y}$ at the fibers at and near the neutral axis, the strains required at the extreme fibers of the section are infinitely large. Secondly, the rectangular stress block can never be achieved without inevitable strain-hardening of the extreme fibers of the beam section. Thus, the representation using rectangular stress blocks deviates from the actual behavior (Figure 10). The beam bending moment equal to the plastic moment value $M_{p}$ can be realized in a section only when a part of it undergoes strain-hardening while some of it still remains elastic; experimental studies (e.g. Popov et al. [10], Chen and Lui [11], Englehardt and Sabol [8]) showed that beam capacities larger than $M_{p}$ are achievable with inelastic deformations corresponding to the drift demands expected by some code guidelines (e.g. UBC [12]; FEMA, [13]). Thus, it is the strain hardening of steel that causes an increase in the member capacity, and hence the demand on connections, under strong seismic shaking over the code-prescribed nominal capacity $M_{p}$. AISC and FEMA (e.g. AISC [14]; FEMA [15]) recommends strain-hardening factors greater than unity to account for beam overstrength, and increase in connection design strength over $M_{p} ; 10-20 \%$ increase is recommended. A simple expression, involving the minimum specified yield and ultimate strengths (e.g. FEMA [16]) is given as 


$$
C_{p r}=\frac{F_{y}+F_{u}}{2 F_{y}}=1+\frac{1}{2}\left(\frac{F_{u}-F_{y}}{F_{y}}\right),
$$

where $F_{y}$ and $F_{u}$ are the specified minimum yield and tensile strengths of the (beam) material, respectively. Later, a more rational approach to estimate $R_{s}$ was presented (e.g. Arlekar and Murty [17]). For any section, normalized moment $M / M_{p}$ versus normalized curvature relations can be generated. $\varphi$ is the curvature of the section, and $\varphi_{y}$, referred to as yield curvature when the farthest material point from the neutral axis reaches yield. Then, the normalized moment $M / M_{p}$ is the strain hardening factor $R_{s}$, and is a measure of strain hardening in the beam. And, $\varphi / \varphi_{y}$ is the curvature ductility $\mu_{\varphi}$. Based on a study of 61 hot-rolled tapered-flange I-sections (Table 1), the expression for strain hardening factor $R_{s}$ was given as (e.g. Goswami, Arlekar and Murty[18]) (Figure 11)

$$
\frac{M}{M_{p}}=R_{s}= \begin{cases}\mu_{\varphi} & \text { for } 0 \leq \mu_{\varphi} \leq \mu_{y} \\ 1 & \text { for } \mu_{y}<\mu_{\varphi} \leq \mu_{s h}, \\ 0.81+2\left(\frac{\mu_{\varphi}}{100}\right)-2\left(\frac{\mu_{\varphi}}{100}\right)^{2}+\left(\frac{\mu_{\varphi}}{100}\right)^{3}-0.3\left(\frac{\mu_{\varphi}}{100}\right)^{4} \text { for } \mu_{s h}<\mu_{\varphi} \leq \mu_{u}\end{cases}
$$

where $\mu_{y}$ is the curvature ductility at idealized yield, $\mu_{s h}$ is the curvature ductility at the beginning of strain-hardening on the idealized curve, and $\mu_{u}$ is the ultimate curvature ductility. From the data of the 61 sections considered, the values of $\mu_{y}, \mu_{s h}$ and $\mu_{u}$ are obtained as $1.0,11.4$ and 150 respectively. Further, curvature ductility $\mu_{\varphi}$ imposed at a section can be estimated from the amount of plastic rotation $\theta_{p}$ required to be developed at the end of the member, using

$$
\mu_{\varphi}=\frac{2 E I \theta_{p}}{M_{p} d}
$$

where $d$ and $E I$ are the depth and flexural rigidity of the member. Early experiments have shown that plastic rotation demand of 0.03-0.04 can be achieved without significant loss in strength (e.g., FEMA [13]). Since Indian steel code specifies no such demand, experiments need to be conducted on MRFs made using the available tapered-flange sections to determine desirable plastic rotations and develop associated design guidelines. Still, using Eq. 3, the curvature ductility $\mu_{\varphi}$ of the sections considered ranges from 7.0 to 29.0 for $\theta_{p}$ varying between 0.01 and 0.04 radians. Then, using Eq. 2, the value of $R_{s}$, hereinafter called the strain-hardening factor, is estimated to be in the range 1.0 to 1.24 for the available tapered-flange I-sections. The above expression for $R_{S}$ was derived for ASTM A36 grade steel with $F_{y}$ equal to $250 \mathrm{MPa}$, and $F_{u} / F_{y}$ as 1.5 . 


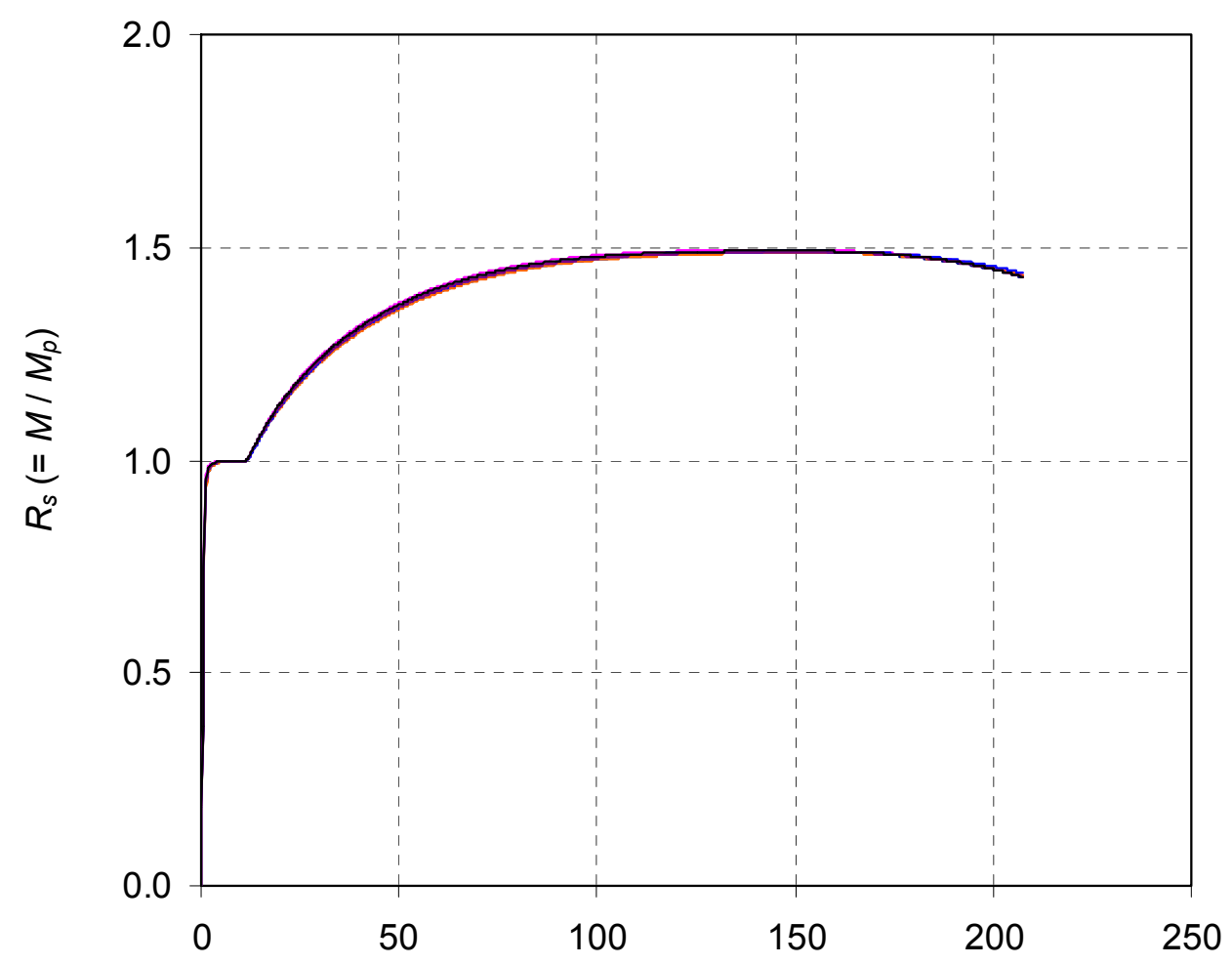

Figure 11. Strain-Hardening of Tapered-Flange I-Sections: Strain-Hardening Factor from Study using 61 Hot-Rolled Tapered-Flange I-Sections with $F_{u} / F_{y}=1.5$

Though member capacity that can be mobilized (and thus, connection design force) is increased due to strain-hardening and uncertainty in material yield strength, section and member instabilities cause reduction of member capacity and connection design force. A compactness factor $R_{c}$, is introduced to account for the reduction in the maximum achievable member capacity owing to premature local buckling given by

$$
R_{c}=\left\{\begin{array}{lc}
1.0 & \text { for } \frac{b}{t} \leq \lambda_{p} \\
1.0-0.2\left\{\frac{(b / t)-\lambda_{p}}{\lambda_{r}-\lambda_{p}}\right\} & \text { for } \lambda_{p}<\frac{b}{t} \leq \lambda_{r} . \\
0.8 & \text { for } \frac{b}{t}>\lambda_{r}
\end{array}\right.
$$

Here, the minimum value of $R_{c}$ is 0.8 . The limiting values for $\lambda_{r}$ and $\lambda_{p}$ are prescribed in the codes. However, the limits prescribed in the codes are originally for the purpose of beam flexural design and thus, will tend to give a conservative underestimate of the member strength. But, in connection design, the upper bound strength is required. Moreover, these values are for prismatic flange and web. For hot-rolled I-sections with tapered flanges, such limits of $\lambda_{r}$ and $\lambda_{p}$ for connection design purpose and dependence of $R_{c}$ on these need to be prescribed.

Using $R_{y}, R_{s}$, and $R_{c}$, the maximum probable member strength, and hence, the maximum probable demand on the connection elements in beam-to-column connections is given by 
$M_{p r}=R_{y} R_{s} R_{c} M_{p}$

Column-to-foundation connection (Figure 8) design on the other hand also requires proper account of the axial load on the column, which is often varying, particularly under strong seismic shaking. Further, interactions between axial force, shear force and bending moment capacities of the section need to be looked into in arriving at the connection design forces. In addition, design codes consider the minimum specified yield strength $F_{y}$ as the limiting strength for capacities and the interactions. This is acceptable for design of the members. However, it is required to properly estimate the maximum possible capacities along with the interactions considering strain-hardening for design of connection elements. Thus, section capacities of tapered-flange I-sections are developed using a fiber model and hysteretic loading and unloading of steel constitutive law (Figure 12). Figure 13 shows typical $P-V-M$ interaction surface of a tapered-flange I-section (e.g., ISMB 600, with section properties as given in Table 1). While developing the $P-V$ - $M$ interaction curves, the following is considered. For a given normal stress $\sigma_{x x}$ (due to axial load and bending moment) in a fiber, the von Mises yield criterion for steel represented by

$\sigma_{x x}^{2}+3 \tau_{x z}^{2}=Y^{2}$

is used to calculate the available shear capacity. Here, $Y$ is taken as the ultimate stress $F_{u}$. The curvature is increased from zero to a maximum value corresponding to the maximum rupture strain $\varepsilon_{r}$ at the extreme fiber, and at each level, the shear and normal capacities are estimated. The uniaxial stress-strain curve of steel (Figure 11) has a drop in the stress beyond the strain corresponding to the ultimate stress. The limiting shear stress from Eq. 6 when $\sigma_{x x}=F_{u}$, is zero. For strains greater than $\varepsilon_{u}$, Eq. 6 suggests that the shear stress $\tau_{x z}$ in fibers is non-zero. However, in this study it is assumed that all fibers having strains beyond $\varepsilon_{u}$ do not have shear capacity. Further, while obtaining the limiting $V-M$ boundary, it is assumed that beam flanges and webs do not undergo buckling. The nominal shear strength $\left(V_{p}=\tau_{y} t_{w} d\right)$ and the nominal bending moment capacity $\left(M_{p}=F_{y} Z\right)$ of the section are used to normalize the shear and moment capacities, respectively. The first yield shear stress corresponding to a state of pure shear is used and defined as $\tau_{y}=F_{y} / \sqrt{3}$.

The most commonly used section capacity interaction in design is the $P-M$ interaction. Figure 14 shows $P$ - $M$ interactions developed for the tapered-flange section considering strain-hardening using the fiber model. Design codes often assume a linear interaction (for ease in design) and uses yield strength as the limiting strength. Figure 14 also shows the linear interaction recommended by the Indian code (IS 800 [4]) along with the scaled interaction up to the ultimate capacity. The code specified curve depicts an average member capacity for moments up to about $M_{p}$. Thus, it underestimates the moment capacity of some members, and hence, connections designed using this interaction would be under-designed. Hence, an upper bound of the $P-M$ interaction curves at zero shear is derived as

$\frac{M}{M_{p}}=\frac{F_{u}}{F_{y}}\left(1-\frac{F_{y}}{F_{u}} \frac{P}{P_{y}}\right)^{1.54}$. 

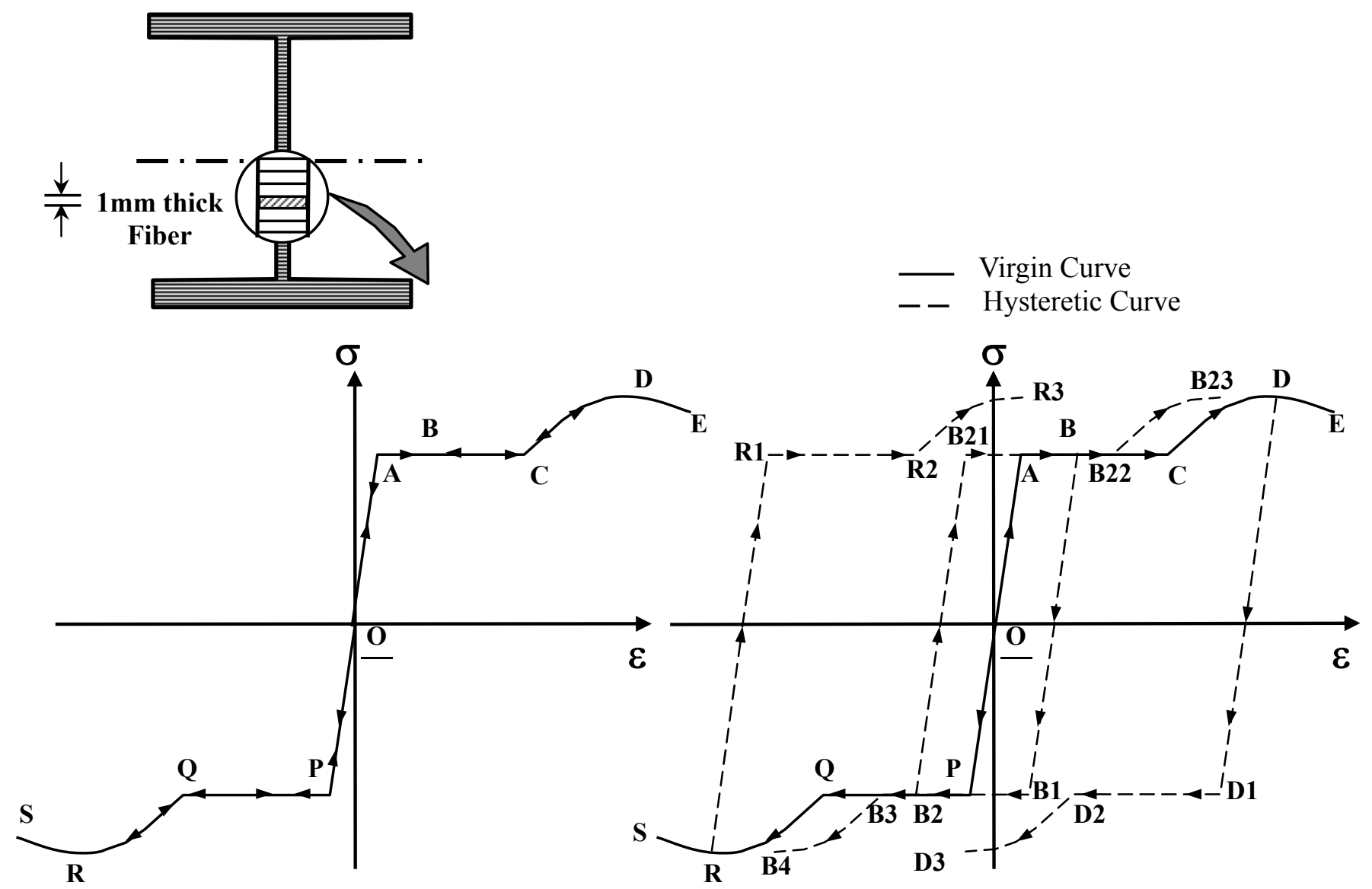

Figure 12. Fiber Model Showing the Discretization of the Beam Section along with the Explicit form of Stress-Strain Relationship for Steel Along with

Schematic Representation of the Loading and Unloading Paths for Steel

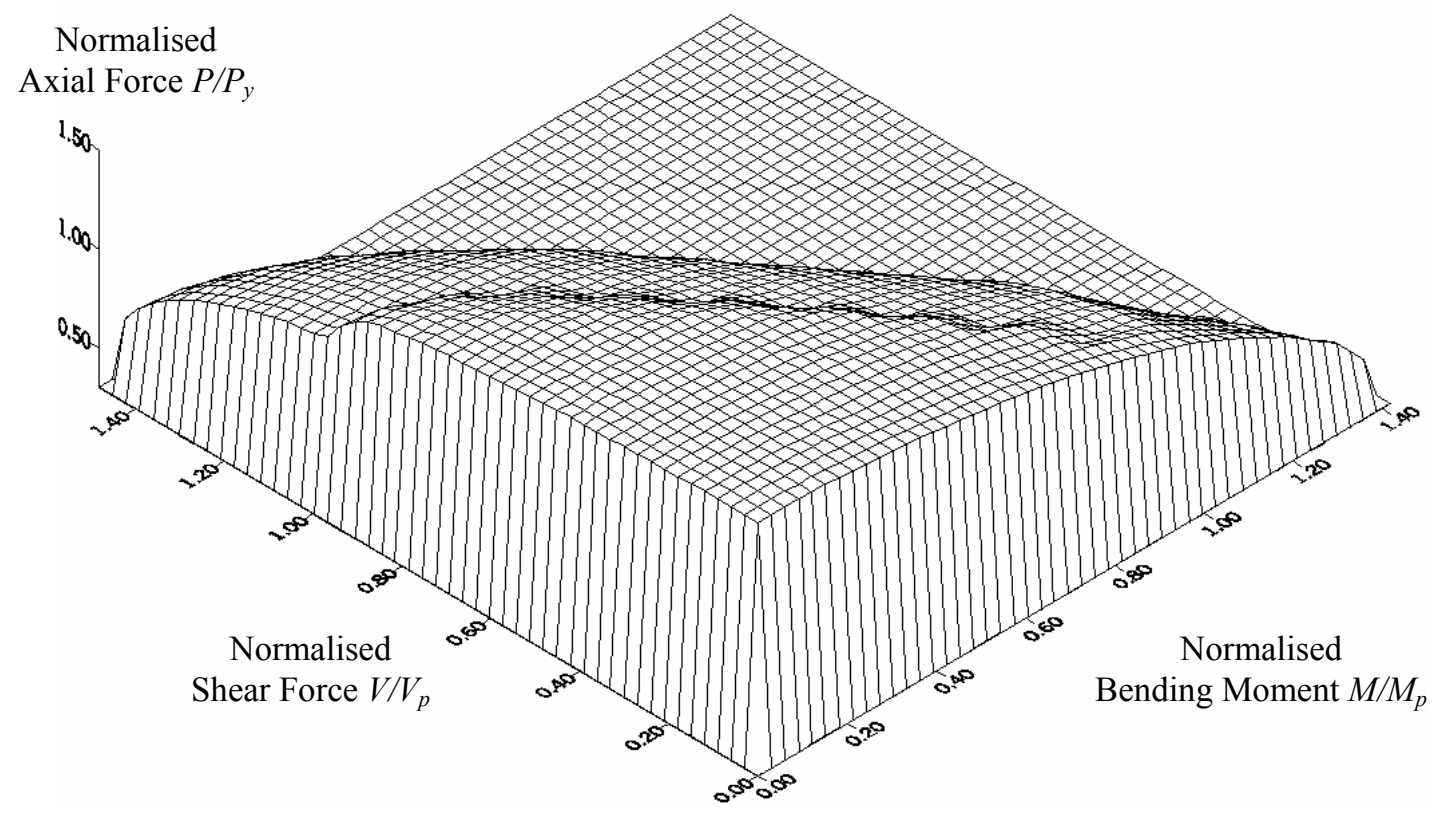

Figure 13. Strength Interaction in ISMB 600: Normalized $P-V-M$ Interaction Surface of ISMB 600 Generated using Hysteretic Stress-Strain Model 


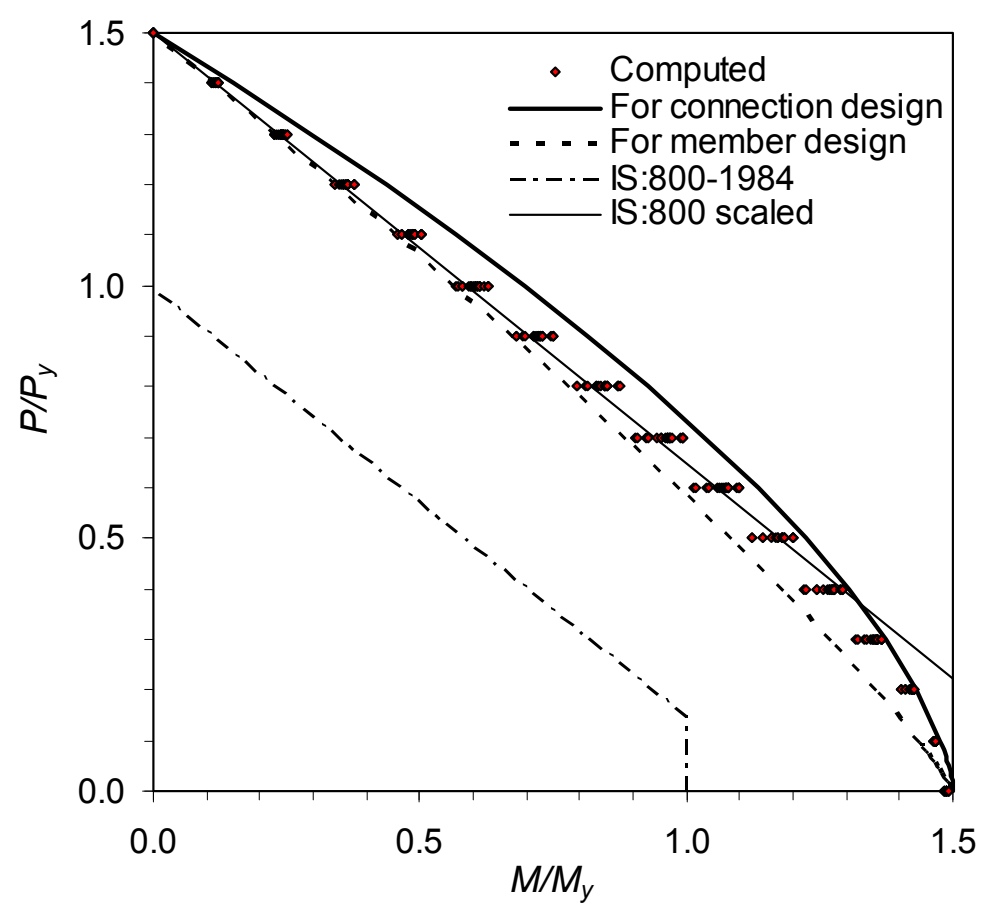

Figure 14. $P-M$ Interaction Curve along with the Actual $P$ - $M$ Points for $V=0$ for Indian Hot Rolled I-Sections

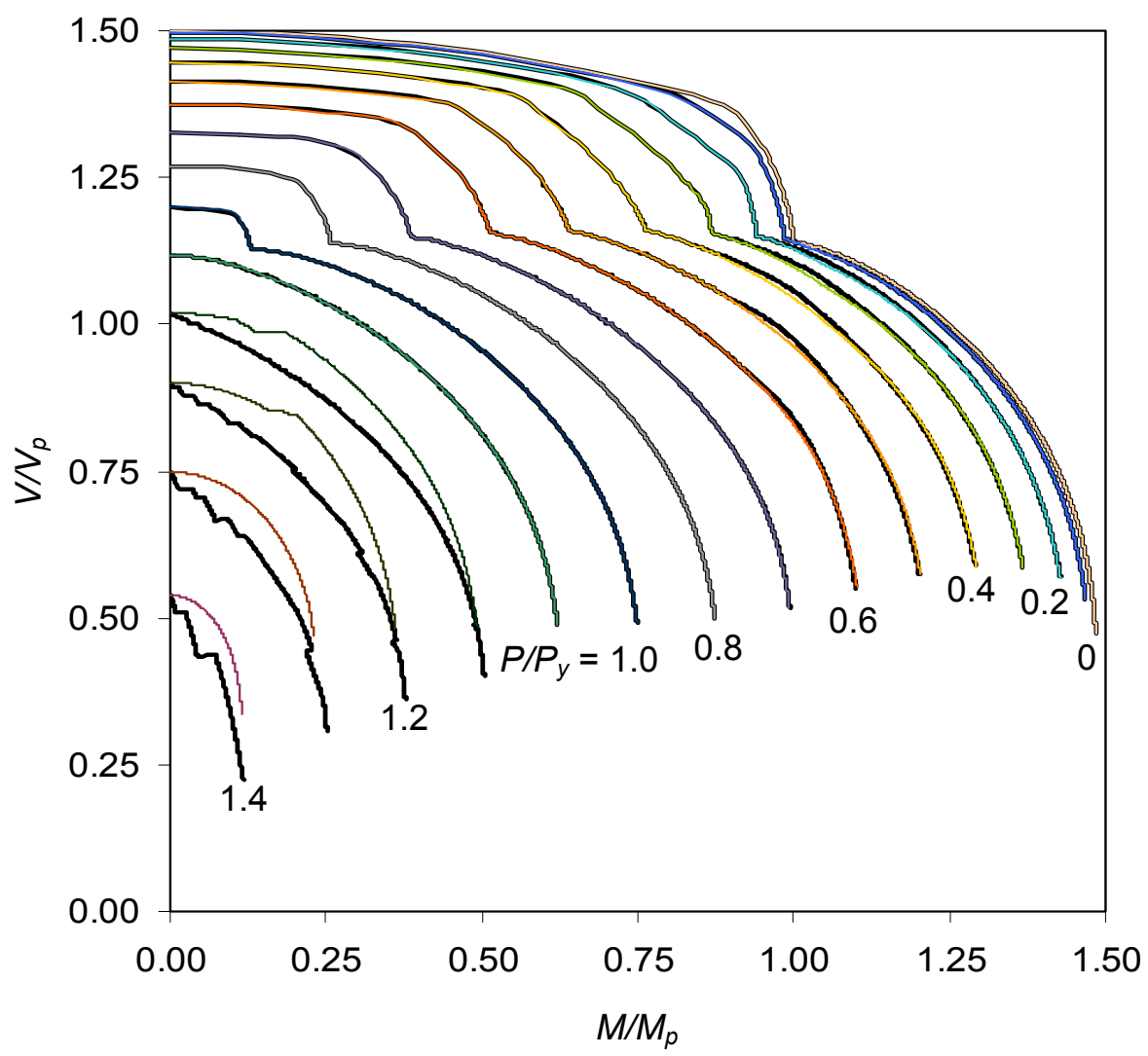

Figure 15. Shear-Moment Interaction showing Normalized $V$ - $M$ Curves for a Typical Tapered-Flange I-Section (ISMB 600) for Different Axial Load Levels with and Without Hysteretic Stress-Strain Ccurve. 
This upper bound limit is conservative for ascertaining the connection demand forces, although, using this for member design would result in an overestimate of the member capacity. Figure 15 shows normalized $V-M$ interaction curves for a typical tapered-flange I-section (ISMB 600) for various levels of the compressive axial loads. The moment is normalized with the nominal plastic moment capacity $M_{p}$ and shear with the nominal shear capacity $V_{p}$. The $V$ - $M$ interaction curves obtained using strain-hardened virgin stress-strain curve are also shown in Figure 15. The $V-M$ curves without hysteretic loading (represented by thinner lines) are higher than the corresponding curves obtained using the hysteretic loading (represented by thicker lines), only when the axial load is higher than the yield load $P_{y}$. Thus, the $V$ - $M$ curves with non-hysteretic loading, commonly used in codes, are acceptable in static design where the axial load does not change or is below the member yield load. However, under earthquake shaking, the axial load can swing by large amount and the $V-M$ curves with hysteretic loading better reflect the actual lower member capacity and should be considered for the member design.

Unlike for beam-to-column connection design, the connection design forces for column-to-foundation design forces needs to account also for the various strength interactions stated above. However, as in beam-to-column connection design, additional strength reductions result due to member instabilities like global flexural buckling in compression and global flexural-torsional buckling. For instance, the reduction due to flexural buckling in compression can be taken into account through a modification factor $R_{\lambda}$ as

$$
R_{\lambda}=\left\{\begin{array}{ll}
0.658^{\lambda_{c}^{2}} & \text { for } \lambda_{c} \leq 1.5 \\
\frac{0.877}{\lambda_{c}^{2}} & \text { for } \lambda_{c}>1.5
\end{array},\right.
$$

where $\lambda_{c}$ is the global slenderness parameter given by

$$
\lambda_{c}=\frac{K L}{r \pi} \sqrt{\frac{F_{y}}{E_{s}}},
$$

in which, $K$ is the effective column length factor, $L$ the length of the column, and $r$ the governing radius of gyration, and $F_{y}$ and $E_{s}$ the yield strength and modulus of elasticity of steel, respectively. Similarly, the reduction due to flexural-torsional buckling can be accounted through a factor $R_{L}$ given by

$$
R_{L}=\left[\frac{\pi^{2} E_{s} C_{w}}{\left(K_{z} L\right)^{2}}+G_{s} J\right] \frac{1}{\left(I_{x}+I_{y}\right) F_{y}},
$$

where $C_{w}$ is the warping constant, $K_{z}$ the effective length factor for torsional buckling, $G_{s}$ the shear modulus of steel, $J$ the torsional constant, and $I_{x}$ and $I_{y}$ the moment of inertia about the $x$ and $y$ axes, respectively. Thus, the maximum probable column moment capacity $M_{p r}^{P}$ under axial load $P$ that can be mobilized (or the design moment for column-to-foundation connection design) is given by

$$
M_{p r}^{P}=R_{y} \operatorname{Min}\left[R_{c} ; R_{\lambda} ; R_{L}\right] M_{p}^{P}
$$


Unlike in Eq. 5, the strain-hardening factor is not explicitly used (in Eq. 11) because with the varying column axial force levels during seismic shaking, the level of strain-hardening also varies. Instead, the capacity curves are developed considering possible strain-hardening.

Using the design forces given by Eqs. 5 or 11, the connections need to be designed. However, in executing the design, various concerns arise in use of tapered-flange sections; it is particularly serious for bolted connections. Typically, the beam flanges are expected to transfer the bending moment, and the beam web the shear forces. However, recent studies have shown that this assumption is not realistic, and a truss analogy model is necessary to represent the realistic flow of forces in the connection (e.g. Lee, Goel and Stojadinovic [19]; Arlekar and Murty [20]). An improved welded cover plated and ribbed moment connection is necessary to transfer the overstrength based design forces (e.g. Arlekar and Murty [20]). Here, the cover plate is designed to transfer part of the bending moment in the form of axial (compressive or tensile) forces, while two outer rib plates are designed to transfer both axial and shear forces (Figure 16).

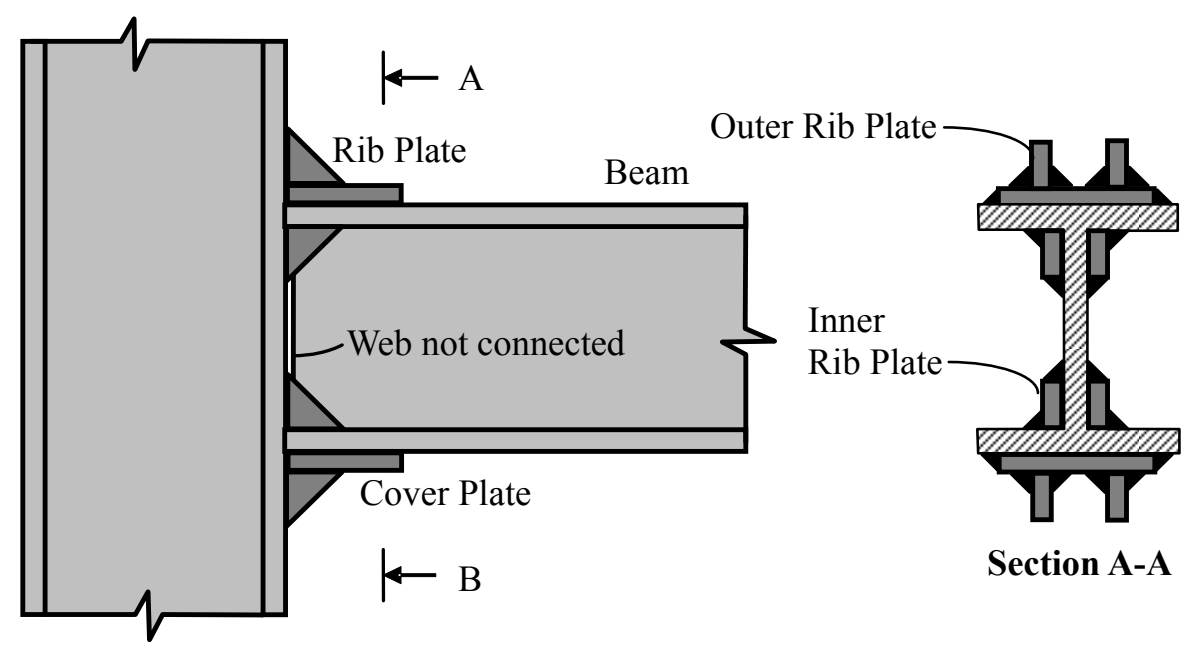

Figure 16. Cover Plated Rib Plated Welded Strong-Axis Moment Connection Configuration in

Parallel Flange Sections: Cover Plates Transfer Part of Moment in the Form of Axial (Compressive and Tensile) Forces while (Outer) Rib Plates Transfer Axial and Shear Forces

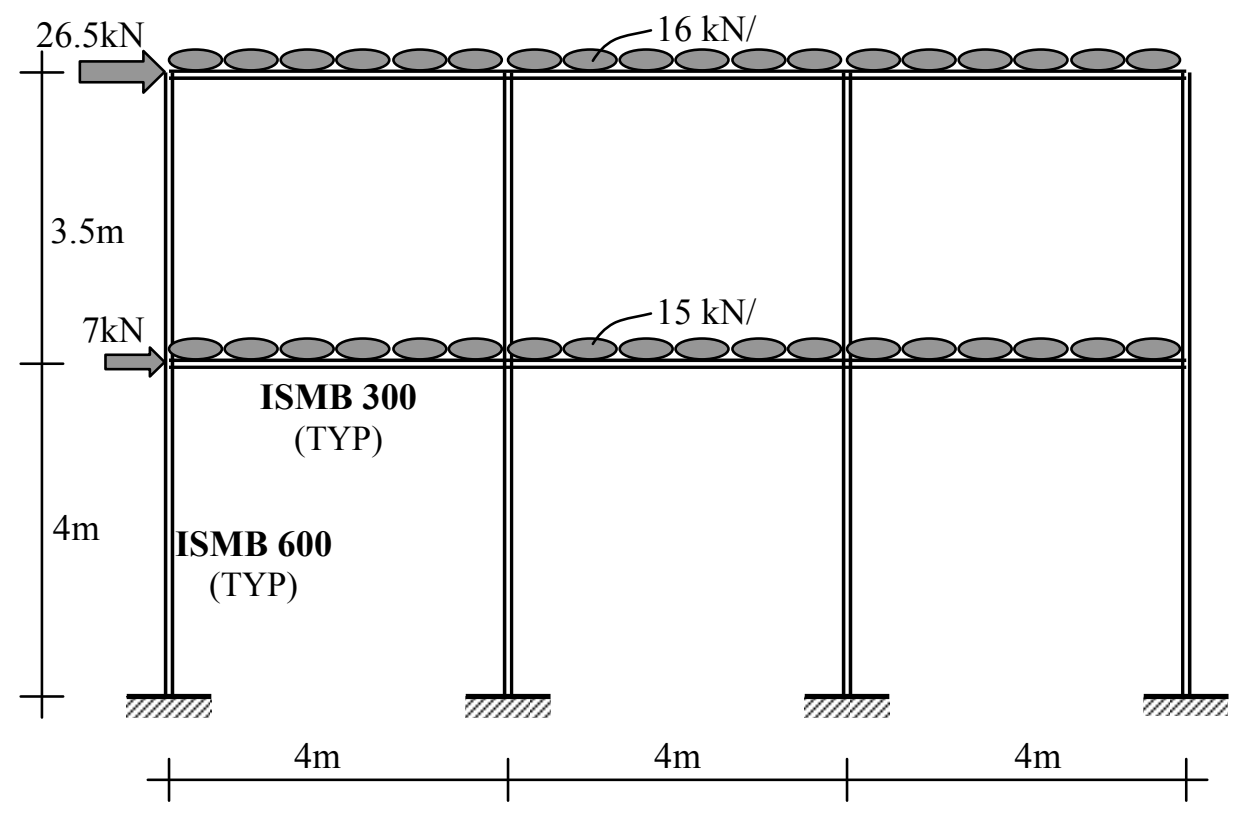

Figure 17. Sample Frame: Member Sizes, Boundary Conditions with Loadings 
Tapered flange sections have small flange widths. Hence, in bolted connections, only a single line of weld is possible on either side of the web leading to long connection region. And, in welded connections, often, there is insufficient space between the two outer rib plates to weld them to the cover plates. In addition, due to tapering of these flanges, additional inner rib plates cannot be provided efficiently; these are crucial in minimizing stress concentration near the weld access holes. The following beam-to-column connection design example highlights the concerns in welded connections.

Figure 17 shows a simple 3-bay 2-storey frame made with Indian tapered-flange I-sections. The bay span considered is $4 \mathrm{~m}$. The uniformly distributed gravity load (including dead load, fraction of live load on roof and floor, and roof finish load) is $16 \mathrm{kN} / \mathrm{m}$ on the roof beam and $15 \mathrm{kN} / \mathrm{m}$ on the floor beam. The frame is considered to be in the most severe seismic zone and analysed for code specified load combinations. The maximum joint moment and shear forces for load combination $1.3(\mathrm{DL}+\mathrm{LL}+\mathrm{EL})$ are respectively $43 \mathrm{kNm}$ and $48 \mathrm{kN}$. The beam-to-column connection is designed for this force.

In the common design practice, members and connections are designed based on the linear static analysis results. The web is considered to carry the shear and the two flanges carry the flexure, in the form of tension and compression. Accordingly, from the static analysis results above, $6 \mathrm{~mm}$ fillet welds of $100 \mathrm{~mm}$ length on both sides of the web are sufficient to carry the shear. The flanges can be connected to the column through a $10 \mathrm{~mm}$ full penetration butt weld, or by $10 \mathrm{~mm}$ fillet weld along the straight portions of the flanges. As there are no particular recommendations for the type of connection arrangement to be adopted in the existing Indian codes, such simple form of connection can be designed still adhering to the code provisions, if desired.

As an alternative, the beam-to-column connections can be designed using plastic theory wherein the connections can be designed for the nominal plastic moment that is to be transmitted from one member to another. Thus, under the condition of an extreme shaking, assuming that plastic hinges are formed at the beam ends, the design forces for connection design is the nominal plastic moment $M_{p}(161.6 \mathrm{kNm})$ of the beam and a shear of $120.6 \mathrm{kN}$, considering the critical sections to lie at the beam-column interface. Thus, now the design shear and moment are increased by 1.5 to 2.8 times over the structural analysis results of the frame discussed earlier, and now, the connection designed earlier becomes inadequate. Further, the code does not specifically say that plastic analysis and design need to be done for seismic conditions. Thus, it remains at the hand of the designer to choose the type of analysis and design one wishes to do, and in the process, the structural safety is put at stake.

As the second alternative, now consider the overstrength based modification factors $R_{y}=1.3, R_{s}=$ 1.24 and $R_{c}=1.0$. The design moment at the column face becomes $261 \mathrm{kNm}$ plus the shear times the length of the connection reinforcement region and plastic hinge length. Thus, there is an increase of more than $62 \%$ in the design moment alone. This can cause premature failure of the connection even before the beam reaches its full plastic capacity resulting in collapse of the structure. Further, simple direct connections (directly welding the beam to the column) do not facilitate smooth flow of forces through the connection region; stress concentration at the beam flange-column flange junction severely affects the functioning of the connection. The cover-plated rib-plated connection with connection length of half the beam depth is an improvement (Figure 16). Using this, the associated shear force increases to $186.5 \mathrm{kN}$, an increase of about $55 \%$ compared to a value of $120.6 \mathrm{kN}$. However, this scheme works best on sections with wide non-tapered flanges. Tapered-flange Indian sections have very small flange width. As such, the available width of cover plate is much less and may be insufficient to transfer the forces in higher structures with higher forces. The example frame is a nominal two-storey lightly loaded structure chosen only with the 
intention to discuss the important issues. Also, due to tapering of these flanges, additional inner rib plates cannot be provided efficiently to further reinforce the connection. These are important for minimizing stress concentrations at and near the weld access holes.

\section{TAPERED FLANGE SECTIONS IN OTHER COUNTRIES}

Tapered flange sections are still listed in different handbooks and codes across America and Europe (e.g., "Standard Beams" in American (AISC [21]) and Canadian [CISC [22]) handbooks, "Joists" in British Standard (BS 4-1 [23]). However, their use as main structural member in MRFs in seismic applications has become extinct. For instance, such sections are currently not available in the Canadian market, while their availability in the American and European market is questionable. Moreover, the maximum depth of the Standard Beams is $622 \mathrm{~mm}$ with flange width of only $204 \mathrm{~mm}$, while that for the Joists, these are $254 \mathrm{~mm}$ and $203 \mathrm{~mm}$, respectively. These are comparable to the Indian standard tapered-flange I-sections. For the already stated reasons, countries with advanced seismic provisions for design of steel structures use only wide-flange hot-rolled sections with uniform thickness flanges (e.g., the American W-shapes, British Universal Beams, and European wide flange HEA, HEB, \& HEM sections).

On the other hand, in some Asian countries in high seismic regions, tapered-flange sections are still manufactured and are being used for structural applications. Possible reasons for this continued use of inappropriate sections include utilization of the old rolling mills without upgrading, lack of awareness towards seismic hazard of the region, and lack of code provisions.

\section{SUMMARY}

Tapered-flange I-sections, of at least a reasonable size, offer low section properties (namely moment of inertia, flange width, and nominal plastic moment capacity), violate stability requirements for stable post-yield behaviour particularly under strong seismic shaking, and offer constructional difficulties. Despite these deficiencies, tapered-flange I-sections are still being used extensively in many Asian countries. Thus, there is an urgent need to stop use of such sections, especially in seismic areas. This can be achieved by disseminating information regarding their deficiencies and challenges in their usage to the industry, architects and design engineers. Also, regional codes and specifications should restrict the use of such sections for seismic applications. Indirectly, this may even open up new opportunities for steel industry to manufacture larger seismically compact sections for the Asian market. 
Table 1. Moment of Inertia and Nominal Plastic Moment Capacity of Indian Tapered-Flange I-Sections.

\begin{tabular}{|c|c|c|c|c|c|c|c|}
\hline $\begin{array}{r}\text { Section } \\
\text { Name }\end{array}$ & $\begin{array}{c}\text { Depth } d \\
(\mathrm{~mm})\end{array}$ & $\begin{array}{c}I_{x x} \\
\left(10^{-6} \mathrm{~m}^{4}\right)\end{array}$ & $\begin{array}{c}M_{p} \\
(\mathrm{kNm})\end{array}$ & $\begin{array}{l}\text { Section } \\
\text { Name }\end{array}$ & $\begin{array}{c}\text { Depth } d \\
(\mathrm{~mm})\end{array}$ & $\begin{array}{c}I_{x x} \\
\left(10^{-6} \mathrm{~m}^{4}\right)\end{array}$ & $\begin{array}{c}M_{p} \\
(\mathrm{kNm})\end{array}$ \\
\hline ISLB 75 & 75 & 0.7 & 5.4 & \multirow{2}{*}{ ISMB 100} & \multirow{2}{*}{100} & \multirow{2}{*}{2.6} & \multirow{2}{*}{14.5} \\
\hline ISLB 100 & 100 & 1.7 & 9.4 & & & & \\
\hline ISLB 125 & 125 & 4.1 & 18.0 & ISMB 125 & 125 & 4.5 & 20.3 \\
\hline ISLB 150 & 150 & 6.9 & 25.4 & ISMB 150 & 150 & 7.3 & 27.3 \\
\hline ISLB 175 & 175 & 11.0 & 34.9 & ISMB 175 & 175 & 12.7 & 41.2 \\
\hline ISLB 200 & 200 & 17.0 & 47.1 & ISMB 200 & 200 & 22.4 & 62.6 \\
\hline ISLB 225 & 225 & 25.0 & 63.5 & ISMB 225 & 225 & 34.4 & 86.0 \\
\hline ISLB 250 & 250 & 37.2 & 84.9 & \multirow{2}{*}{ ISMB 250} & \multirow{2}{*}{250} & \multirow{2}{*}{51.3} & \multirow{2}{*}{114.9} \\
\hline ISLB 275 & 275 & 53.8 & 111.3 & & & & \\
\hline ISLB 300 & 300 & 73.3 & 138.9 & \multirow{2}{*}{ ISMB 300} & \multirow{2}{*}{300} & \multirow{2}{*}{86.0} & \multirow{2}{*}{161.6} \\
\hline ISLB 325 & 325 & 98.8 & 172.8 & & & & \\
\hline ISLB 350 & 350 & 131.6 & 212.2 & ISMB 350 & 350 & 136.3 & 219.6 \\
\hline ISLB 400 & 400 & 193.1 & 273.5 & ISMB 400 & 400 & 204.6 & 290.5 \\
\hline ISLB 450 & 450 & 375.4 & 348.1 & ISMB 450 & 450 & 303.9 & 383.0 \\
\hline ISLB 500 & 500 & 385.8 & 440.3 & ISMB 500 & 500 & 452.2 & 512.8 \\
\hline ISLB 550 & 550 & 531.6 & 553.7 & ISMB 550 & 550 & 648.9 & 670.5 \\
\hline ISLB 600 & 600 & 758.7 & 696.6 & ISMB 600 & 600 & 918.1 & 867.8 \\
\hline \multirow{3}{*}{ ISWB 150} & \multirow{3}{*}{150} & \multirow{3}{*}{8.4} & \multirow{3}{*}{31.5} & ISHB 150 & 150 & 14.6 & 53.4 \\
\hline & & & & ISHB 150 & 150 & 15.4 & 56.8 \\
\hline & & & & ISHB 150 & 150 & 164 & 605 \\
\hline ISWB 175 & 175 & 15.1 & 48.4 & -3 & & 10.4 & \\
\hline \multirow{2}{*}{ ISWB 200} & \multirow{2}{*}{200} & \multirow{2}{*}{26.3} & \multirow{2}{*}{73.0} & ISHB 200 & 200 & 36.1 & 98.9 \\
\hline & & & & ISHB 200 & 200 & 37.2 & 102.4 \\
\hline \multirow{2}{*}{ ISWB 225} & \multirow{2}{*}{225} & \multirow{2}{*}{39.2} & \multirow{2}{*}{96.9} & ISHB 225 & 225 & 52.8 & 128.5 \\
\hline & & & & ISHB 225 & 225 & 54.8 & 134.1 \\
\hline \multirow{2}{*}{ ISWB 250} & 250 & 50 & 1210 & ISHB 250 & 250 & 77.4 & 169.2 \\
\hline & 250 & 39.4 & 131.8 & ISHB 250 & 250 & 79.8 & 175.5 \\
\hline ICWDD 200 & 200 & 00 ? & $102 ?$ & ISHB 300 & 300 & 125.5 & 229.3 \\
\hline ISWB 300 & 300 & 98.2 & 182.3 & ISHB 300 & 300 & 129.5 & 238.1 \\
\hline ICUND 250 & & & 2470 & ISHB 350 & 350 & 191.6 & 301.6 \\
\hline ISWB 350 & 350 & 155.2 & 247.9 & ISHB 350 & 350 & 198.0 & 313.5 \\
\hline ICUND 400 & 100 & 2242 & 2280 & ISHB 400 & 400 & 280.8 & 388.7 \\
\hline $1 \mathrm{ISWB} 400$ & 400 & 234.3 & 328.0 & ISHB 400 & 400 & 288.2 & 402.7 \\
\hline ICUD 150 & 150 & 2506 & 1250 & ISHB 450 & 450 & 392.1 & 485.5 \\
\hline $15 \mathrm{WB} 450$ & 450 & 350.6 & 435.8 & ISHB 450 & 450 & 403.5 & 502.2 \\
\hline ISWB 500 & 500 & 522.9 & 585.1 & & & & \\
\hline ISWB 550 & 550 & 749.1 & 760.8 & & & & \\
\hline ISWB 600_1 & 600 & 1062.0 & 987.8 & & & & \\
\hline ISWB 600_2 & 600 & 1156.3 & --- & & & & \\
\hline
\end{tabular}


Table 2. Moment of Inertia and Nominal Plastic Moment Capacity of Some Representative AISC I-Sections.

\begin{tabular}{|l|c|c|c|}
\hline $\begin{array}{l}\text { Section } \\
\text { Name }\end{array}$ & $\begin{array}{c}\text { Depth } d \\
(\mathrm{~mm})\end{array}$ & $\begin{array}{c}I_{x x} \\
\left(10^{-6} \mathrm{~m}^{4}\right)\end{array}$ & $\begin{array}{c}M_{p} \\
(\mathrm{kNm})\end{array}$ \\
\hline W $4 \times 13$ & 106 & 4.7 & 25.7 \\
\hline W $5 \times 19$ & 131 & 10.9 & 47.5 \\
\hline W $6 \times 25$ & 162 & 22.2 & 77.4 \\
\hline W $8 \times 67$ & 229 & 113.2 & 287.6 \\
\hline W $16 \times 100$ & 431 & 620.2 & 811.2 \\
\hline W $18 \times 311$ & 567 & 2897.0 & 3084.9 \\
\hline W $21 \times 402$ & 661 & 5078.0 & 4629.4 \\
\hline W $24 \times 492$ & 753 & 7950.0 & 6350.0 \\
\hline W 27 $\times 539$ & 826 & 10613.9 & 7701.9 \\
\hline W $30 \times 581$ & 899 & 13735.6 & 9053.9 \\
\hline W $33 \times 619$ & 977 & 17398.5 & 10487.7 \\
\hline W $40 \times 655$ & 1108 & 23517.1 & 12536.1 \\
\hline
\end{tabular}

\section{LIST OF SYMBOLS}

The following symbols are used in this paper:

$C_{p r} \quad$ Factor to account for possible strain-hardening

$C_{w} \quad$ Warping constant

E Modulus of elasticity

$E_{s} \quad$ Modulus of elasticity of steel

$F_{u} \quad$ Ultimate (tensile) strength

$F_{y} \quad$ Minimum specified yield strength

$G_{s} \quad$ Shear modulus of steel

I Moment of inertia

$I_{x}, I_{y} \quad$ Moment of inertia about $x$ and $y$ axes

$I_{x x} \quad$ Moment of inertia about strong axis of bending

$J \quad$ Torsional constant

$K \quad$ Effective column length factor

$L \quad$ Length of column

$M \quad$ Bending moment

$M_{p} \quad$ Nominal plastic moment capacity

$M_{p r} \quad$ Maximum probable overstrength based moment

$M_{y} \quad$ Yield moment

$P \quad$ Axial load

$P_{y} \quad$ Axial yield load

$R \quad$ Strength modification factor

$R_{c} \quad$ Strength modification factor to account for compactness of section

$R_{s} \quad$ Strength modification factor due to strain-hardening

$R_{y} \quad$ Strength modification factor due to uncertainty in material yield strength

$R_{L} \quad$ Strength modification factor due to account for flexural-torsional buckling

$R_{\lambda} \quad$ Strength modification factor due to account for flexural buckling in compression 
$V \quad$ Shear force

$V_{p} \quad$ Section plastic shear capacity using minimum specified yield

$V_{p r} \quad$ Connection design shear (equilibrium compatible shear corresponding to overstrength based moment at member ends)

$Y \quad$ Limiting strength used in von Mises yield criterion

$Z \quad$ Plastic section modulus

$b \quad$ Width of plate element; width of flange of section

$d \quad$ Depth of section

$r \quad$ Radius of gyration

$t \quad$ Thickness of plate element

$t_{w} \quad$ Thickness of web

$\Delta \quad$ Deformation

$\varepsilon \quad$ Strain

$\varepsilon_{r} \quad$ Rupture strain

$\varepsilon_{s h} \quad$ Strain at initiation of strain-hardening

$\varepsilon_{u} \quad$ Strain at maximum stress

$\varepsilon_{y} \quad$ Yield strain

$\lambda$ Slenderness parameter

$\lambda_{c} \quad$ Global slenderness parameter

$\lambda_{p} \quad$ Limiting slenderness parameter for compact section

$\lambda_{p s} \quad$ Limiting slenderness parameter for compact section with minimum guaranteed plastic rotation capacity

$\lambda_{r} \quad$ Limiting slenderness parameter for non-compact section

$\varphi \quad$ Curvature

$\varphi_{y} \quad$ Yield curvature

$\mu \quad$ Ductility

$\mu_{s h} \quad$ Curvature ductility at initiation of strain-hardening

$\mu_{u} \quad$ Ultimate curvature ductility

$\mu_{y} \quad$ Curvature ductility at idealized yield

$\mu_{\varphi} \quad$ Curvature ductility

$\theta_{p} \quad$ Plastic rotation

$\sigma \quad$ Stress

$\sigma_{x x} \quad$ Normal stress

$\tau_{x z} \quad$ Shear stress

$\tau_{y} \quad$ Design shear stress

\section{REFERENCES}

[1] IS 1893 Part 1, "Criteria for Earthquake Resistant Design of Structures, Part 1: General Provisions and Buildings", Bureau of Indian Standards, New Delhi, 2002.

[2] AISC, "Specification for Structural Steel Buildings", American Institute of Steel Construction, Inc., Illinois, USA, 2005.

[3] AISC, "Seismic Provisions for Structural Steel Buildings", American Institute of Steel Construction, Inc., Illinois, USA, 2005.

[4] IS 800-1984, "Indian Standard Code of Practice for General Construction in Steel", Bureau of Indian Standards, New Delhi, 1995.

[5] SP: 6(1), "Indian Standard Handbook for Structural Engineers: Structural Steel Sections", Indian Standards Institution, New Delhi, 1964. 
[6] Paul, S., Murty, C.V.R. and Jain, S.K., "Drift-based Re-sizing of Steel Frames Including Joint Deformations,” The Bridge and Structural Engineer, The Journal of ING-IABSE, 2000, Vol. 81, pp. 91-100.

[7] Penelis, G.G. and Kappos, A.J., "Earthquake - Resistant Concrete Structures”, E \& FN Spon, Great Britain, 1997.

[8] Englehardt, M.D. and Sabol, T.A., "Reinforcing of Steel Moment Connections with Cover Plates: Benefits and Limitations," Engineering Structures, 1998, Vol. 20, No. 4-6, pp. 249-260.

[9] Malley, J.O. and Frank, K., "Materials and Fracture Investigations in the FEMA/SAC PHASE 2 Steel Project," Proceedings of the 12th World Conference on Earthquake Engineering, 12WCEE, Paper No. 2544, Auckland, New Zealand, 2000.

[10] Popov, E.P., Amin, N.R., Louie, J.C. and Stephen, R.M., "Performance of Large Beam-to-Column Assemblies," Engineering Journal, AISC, 1986, First Quarter, pp. 9-23.

[11] Chen, W.F., and Lui, E.M., "Static Flange Moment Connections," Journal of Constructional Steel Research, 1988, Vol. 10, pp. 39-88.

[12] UBC, "Uniform Building Code", 1997 Edition, International Conference of Building Officials, Whittier, CA, USA.

[13] FEMA 267, "Interim Guidelines: Evaluation, Repair, Modification and Design of Welded Steel Moment Frame Structures," Report No. SAC-95-02, SAC Joint Venture, CA, USA, 1995.

[14] AISC, "Seismic Provisions for Structural Steel Buildings", American Institute of Steel Construction, Inc., Illinois, USA, 1997.

[15] FEMA 267, "Interim Guidelines Advisory No. 2 - Supplement to FEMA-267 Interim Guidelines: Evaluation, Repair, Modification and Design of Welded Steel Moment Frame Structures," Report No. SAC-99-01, Federal Emergency Management Agency, USA, 1999.

[16] FEMA 350, "Recommended Seismic Design Criteria for New Steel Moment-Frame Buildings," SAC Joint Venture, CA, USA, 2000.

[17] Arlekar, J.N. and Murty, C.V.R., "Capacity Design of Welded Steel MRF Connections," Proceedings of the 4th International Conference on Behaviour of Steel Structures in Seismic Areas (STESSA 2003), 9-12 June 2003, Naples, Italy.

[18] Goswami, R., Arlekar, J.N. and Murty, C.V.R., "Concerns on seismic moment-shear connections using available Indian hot-rolled I-sections," Journal of Structural Engineering, SERC Madras, December 2005 - January 2006, Vol. 32, No. 5, pp. 343-349.

[19] Lee, K.H., Goel, S.C. and Stojadiovic, B., "Boundary Effects in Steel Moment Connections," Paper No. 1098, Proceedings of the 12th World Conference on Earthquake Engineering, Auckland, New Zealand, 2000.

[20] Arlekar, J.N. and Murty, C.V.R., "Improved Truss Model for Design of Welded Steel Moment-Resisting Frame Connections," Journal of Structural Engineering, ASCE, March 2004, Vol. 130, No. 3, pp. 498-510.

[21] AISC, "Manual of Steel Construction", LRFD, 3rd Edition, American Institute of Steel Construction, Inc., Illinois, USA, 2003.

[22] CISC, "Handbook of Steel Construction", 8th Edition, Canadian Institute of Steel Construction, Toronto, Canada, 2004.

[23] BS 4-1, "Structural Steel Sections", Specification for Hot-Rolled Sections, British Standards Institution, London, UK, 2005. 